\title{
O desenvolvimento da competência linguístico-comunicativa de alunos de Letras em curso temático baseado em tarefas
}

\author{
Rita de Cássia Barbirato \\ Universidade Federal de São Carlos \\ ritabarbi.m@gmail.com
}

Elaine Regina Cassoli

Faculdades Integradas de Jahu (Fatec)

e.cassoli@gmail.com

\section{Resumo}

Esta pesquisa, qualitativa e de base etnográfica e interpretativista, teve como objetivo analisar como se dá o desenvolvimento da competência comunicativa (CC) em aprendizes de curso de Letras de contexto adverso de uma faculdade particular do centro-oeste paulista durante participação em um Planejamento Temático Baseado em Tarefas para o ensino-aprendizagem de inglês. Para a coleta de dados foram utilizados testes cloze inicial e final, avaliações escritas ao longo do processo, gravações em áudio das tarefas, posteriormente transcritas para análise, e questionários aplicados aos discentes em momentos diferentes do curso. $\mathrm{O}$ arcabouço teórico fundamenta-se em autores como: Almeida Filho (1992; 2008); Barbirato (1999; 2005); Candlin (1987); Crandall (1994; 2000 ); Ellis (2003); Nunan (1989; 1993); Prabhu (1987); Skehan (1999), entre outros. A análise dos resultados demonstrou que o trabalho em que coexistiram ensino temático e tarefas comunicativas pode ser uma alternativa para o ensino-aprendizagem de língua inglesa no contexto investigado, em que havia limitação linguístico-comunicativa prévia na língua-alvo na maioria dos participantes, com fortes indícios de que tal ensino tenha potencial para colaborar para a aquisição de LE no contexto estudado.

Palavras-chave: Ensino temático. Tarefas comunicativas. Desenvolvimento da competência comunicativa. Alunos de Letras.

\section{Abstract}

This qualitative, ethnography-based, interpretational research aimed to analyze how the development of the communicative competence occurs with 


\section{O desenvolvimento da competência}

Letters students. The students participating in the research were Letters majors in a private college in the Midwest region of São Paulo and came from adverse contexts. For data collection, we used an initial and a final cloze test, written tests (along the course), audio recorded lessons and questionnaires (which were later transcribed and analyzed in different moments of the course). The theoretical research was based on the following authors: Almeida Filho (1992; 2008); Barbirato (1999; 2005); Candlin (1987); Crandall (1994; 2000 ); Ellis (2003); Nunan (1989; 1993); Prabhu (1987); Skehan (1999), and others. The result analysis showed that the work with content- and task- based instruction can be an alternative for the analyzed context, in which students had previous limited knowledge about English. This result strongly signals that such instruction can contribute for language acquisition in such difficult contexts.

Keywords: Content-based instruction. Communicative tasks. Communicative competence. Letters majors.

\section{Contextualização da pesquisa}

Analisamos neste artigo o desenvolvimento da competência linguístico-comunicativa (CLC) em experiência de ensino de língua inglesa por meio do uso de um planejamento temático baseado em tarefas comunicativas com foco no sentido para alunos de contexto adverso $^{1}$ do terceiro ano de Letras (noturno) de uma faculdade particular do interior paulista, com o objetivo de averiguar a influência que uma proposta de ensino como essa pode ter no desenvolvimento da CLC desses alunos.

De modo geral, os aprendizes de línguas, tanto aqueles que aprendem a língua para ensiná-la quanto aqueles que a aprendem para uso comunicativo, almejam adquirir a CLC por acreditar ser essa a mais importante das competências, às vezes até julgando, de maneira equivocada, que ela é composta apenas da habilidade oral.

Tal crença, em contextos de aprendizagem não formadores de professores, pode ser realmente o nirvana dos aprendizes. Porém, no

\footnotetext{
${ }^{1}$ Alunos de contexto adverso nesta pesquisa são aqueles que, apesar de terem sido expostos ao ensino da língua inglesa ao longo dos ensinos fundamental e médio e dos primeiros anos da graduação, apresentam nível limitado de comunicação na língua-alvo.
} 
contexto em que escolhemos trabalhar - de alunos de curso de Letras que aprendem a língua para ensiná-la - a aquisição não pode, de maneira alguma, restringir-se à fala. Sabemos que outras competências são fundamentais na formação do professor, todavia nosso foco aqui é o desenvolvimento da CLC de alunos universitários de contexto adverso para se aprender Língua Estrangeira (LE), no caso desta pesquisa, a língua inglesa.

A fim de atingir esse objetivo, analisamos, com fundamento em um estudo qualitativo de base etnográfica, como ocorre (ou se ocorre) o desenvolvimento dessa competência quando alunos do contexto escolhido participam de um curso temático $\left(\mathrm{CBI}\right.$ ou CBT) ${ }^{2}$ baseado em tarefas comunicativas (doravante TBLT) ${ }^{3}$ com foco no sentido, por acreditarmos que esse tipo de ensino pode contribuir de forma relevante para a aquisição de língua estrangeira.

Atualmente, Planejamentos Temáticos Baseados em Tarefas Comunicativas têm sido apontados na literatura da área de ensino e aprendizagem de LE como detentores de grande potencial comunicativo e são foco de muitas pesquisas (Skehan, 1999). Esses planejamentos possuem características que se enquadram nos objetivos do ensino comunicativo de línguas (doravante CLT) ${ }^{4}$ considerando-se que esse visa, entre outros princípios, ao ensino com foco no significado e na interação propositada de sujeitos na LE.

De acordo com Almeida Filho (2008), nesse modelo de ensino as experiências de aprender são organizadas em torno de atividades relevantes, tarefas de real interesse e/ou necessidades do aluno para que ele esteja apto a usar a língua-alvo e a realizar ações do mundo real na interação com outros falantes-usuários dessa língua.

${ }^{2}$ Usaremos a teminologia inglesa CBT (Content-Based Teaching) para nos referirmos ao Ensino Baseado em Conteúdo, de acordo com Richards e Rodgers (2001). O CBT é uma subdivisão, uma possibilidade do CBI (Content-Based Instruction).

3 Doravante utilizaremos a terminologia em inglês TBLT (Task-Based Language Teaching) para nos referirmos ao Ensino Baseado em Tarefas Comunicativas.

${ }^{4}$ Nesta pesquisa utilizaremos a terminologia em inglês CLT (Communicative Language Teaching) para nos referirmos ao Ensino Comunicativo de Línguas. 
Entretanto, o CLT, bem como o PTBT, ${ }^{5}$ vem sofrendo, ao longo dos anos, críticas de vários autores, entre os quais Harley (1992), que discorrem sobre limitações quanto à competência comunicativa atingida no âmbito gramatical. Long e Robinson (1998), por sua vez, afirmam que o foco da abordagem ${ }^{6}$ comunicativa é o significado, tão limitado quanto o foco na gramática da abordagem tradicional, e que falha em desenvolver nos aprendizes a acuidade, resultando em um tipo de produção linguística inadequado e limitado, com muitos erros e apoiado no uso de estratégias de comunicação.

No entanto, alguns autores (ELLIS, 2003; VAN DEN BRANDEN, 2007; WILLIS; WILLIS, 2007) são favoráveis à utilização desse tipo de planejamento. Stern (1987) afirma que, além de favorecer a aprendizagem subconsciente, há outros argumentos em favor do planejamento de cursos e métodos comunicativos. De acordo com o mesmo autor, se a linguagem for apresentada apenas como um código por meio de exercícios formais, estudo de vocabulário e ensaio de funções específicas, o aluno nunca será confrontado com situações reais de uso da língua.

Assim, nosso interesse em investigar este tema centra-se em, mediante dados empíricos, analisar em que extensão essa crítica pode ser verdadeira ou não, por defendermos que o uso do planejamento escolhido pode contribuir para o desenvolvimento da acuidade dos aprendizes.

Consonante com a justificativa deste estudo, esboçada anteriormente, esta investigação buscou analisar a influência que um planejamento temático baseado em tarefas comunicativas com foco no sentido pode ter no desenvolvimento da CLC em alunos de contexto adverso do terceiro ano do curso de Letras noturno de uma faculdade particular do interior paulista.

Desse modo, as questões a seguir emergiram para orientar a realização da pesquisa:

1. Que influência a proposta de ensino de uma nova língua (inglês), que consiste em aulas temático-comunicativas baseadas em tarefas com foco no sentido, pode ter no desenvolvimento da CLC dos

\footnotetext{
${ }^{5}$ Planejamento(s) Temático(s) Baseado(s) em Tarefas Comunicativas.

${ }^{6}$ Nesta pesquisa utilizamos os termos ensino e planejamento como sinônimos de método ou abordagem.
} 
alunos de um curso de Letras ao longo de dois semestres?

1.1. Há registro/evidência de melhora no desenvolvimento da CLC atingida pelos alunos?

Nas próximas seções apresentamos os pressupostos teóricos que orientam este estudo.

\section{Arcabouço teórico que sustenta a pesquisa}

\subsection{O ensino/instrução baseado em conteúdo}

O ensino ou instrução de línguas por conteúdo é aquele que tem por foco o conteúdo em vez das estruturas linguísticas, ou seja, é aprender sobre algo e, consequentemente, adquirir a língua-alvo. Esse ensino integra, no contexto de ensino de uma L2/LE, tópicos ou tarefas de conteúdo(s) de outra(s) disciplina(s), ou temas atuais, polêmicos, de interesse do aluno ou para ele relevantes.

Os pressupostos desse ensino são a linguagem como fenômeno social e discursivo e o contexto multilíngue e multicultural, com base no qual se constrói significado e se (res)significa o mundo.

O grande desafio desse tipo de instrução está na questão: como pode o ambiente da sala de aula confirmar a integração social da linguagem de forma que facilite aos alunos adquirir competências confortavelmente, ou até mesmo o letramento de alto nível cultural numa outra língua?

Tomando-se por base essa pergunta, sugere-se a utilização de tarefas comunicativas para acompanhar o $\mathrm{CBT}^{7}$, por promoverem oportunidades de interação social, contextualização cultural e produção oral e escrita. A viabilização do ensino baseado em conteúdo exige problematizações, que são as tarefas, pois estas são atividades que apresentam problemas que requerem discussão, negociação e trabalho convergente de um grupo. Com base no conhecimento do conteúdo, o aluno pode aprender a expressar opiniões, e dessa forma acreditamos que o Ensino Baseado em Tarefas, juntamente com o Ensino Temático,

\footnotetext{
${ }^{7}$ Utilizamos neste estudo CBT (Content-Based Teaching) e CBI (ContentBased Instruction) como sinônimos.
} 
possa constituir-se em uma alternativa promissora para o processo de desenvolvimento da CLC dos aprendizes.

Nesse tipo de ensino há a versão fraca e a versão forte, assim como no CLT e no TBLT. Na versão fraca desenvolve-se a proficiência comunicativa dos aprendizes na língua-alvo por meio de um plano de curso organizado em torno da aprendizagem de informações e habilidades relevantes (ex.: cursos baseados em temas, textos específicos de uma área, interesse do grupo, conteúdo de uma instituição regular em outra disciplina), porém o foco é a língua, e o tema serve de pretexto para aprendê-la.

$\mathrm{Na}$ versão forte o foco principal é o assunto de uma disciplina específica (language-sensitive content course), e a atenção dos alunos está voltada para o sentido. Como exemplos podemos citar os programas de cursos nos quais se estuda com alunos nativos e o professor fornece algumas explicações adaptadas quando necessário; os programas de imersão - alunos de L2 -, nos quais as aulas são dadas na LE, em geral por falantes nativos; e os programas póssecundários (LAC - Languages Across the Curriculum), que consistem em disciplinas ensinadas por meio da língua-alvo.

Contudo, a versão forte do CBT não é a mais utilizada no nosso contexto de LE, que é o ensino da língua-alvo em um país onde tal língua não é oficial, do que resulta a denominação LE (língua estrangeira). Por esse motivo, utilizamos a versão fraca do CBT/CBI nesta pesquisa.

No CBT avaliam-se os alunos pelo conhecimento do conteúdo ensinado, enquanto no Ensino Baseado na Língua os alunos são avaliados quanto às habilidades ou à proficiência na língua.

Reconhecendo a necessidade de integração tema-tarefa e do uso de planejamentos que integrem essas duas dimensões, discutiremos, brevemente, na próxima seção o conceito de tarefa.

\subsection{As tarefas comunicativas}

De acordo com Ellis (2003), definir o termo tarefa tem sido uma questão polêmica na pesquisa sobre aquisição de línguas, não havendo ainda consenso entre os pesquisadores. O fato de a definição do termo ser problemática vem resultando em diferentes maneiras de utilizá-lo e significá-lo. Ellis (2003) argumenta que há várias 
definições de diversos autores (NUNAN, 1989; PRABHU, 1987, WILLIS, 2007) envolvendo dimensões variadas, que compreendem o escopo da tarefa, a perspectiva na qual é vista, sua autenticidade, as habilidades linguísticas exigidas para desempenhá-la e os processos psicológicos envolvidos na sua realização e resultado.

Concordamos com Ellis (2003, p. 3) quando este define tarefa como "atividade que focaliza primariamente o significado e o uso da língua-alvo", bem como quando define exercícios como atividades "que focalizam primariamente a forma". Também concordamos com esse autor quando ele reconhece que tanto exercícios quanto tarefas têm por objetivo ensinar a língua, porém a diferença está na maneira como esse propósito é alcançado.

Defendemos que a restrição do termo tarefa às atividades primariamente voltadas para o sentido não implica que a forma nunca possa ser abordada, pois ela o será sempre que houver necessidade durante o uso da língua-alvo na realização da tarefa. Não se trata tampouco de mesclar tarefas que focalizam a forma ou o sentido separadamente; trata-se, sim, de tomar por base sempre o sentido e de abordar a forma quando necessário.

Outra diferença do propósito da tarefa refere-se ao papel que os alunos desempenham durante sua realização, porque a tarefa exige que os aprendizes desempenhem o papel de "usuários da língua" (ELLIS, 2003, p. 3), utilizando os mesmos processos comunicativos envolvidos nas atividades que acontecem fora da sala de aula. Em contrapartida, os exercícios exigem que os participantes atuem como "aprendizes", em um processo no qual a aprendizagem é intencional.

Nesse sentido, Widdowson (1998) apresenta-nos uma distinção muito elucidativa entre tarefa e exercício. Para ele, o que diferencia tarefa de exercício é a maneira de entender as habilidades linguísticas, que nas tarefas são desenvolvidas por meio de atividade comunicativa e nos exercícios são entendidas como pré-requisito para se engajar na comunicação. Desse modo, consideramos os exercícios como précomunicativos, ou seja, uma preparação para a comunicação. É o critério perspectiva que, segundo Ellis (2003), se refere ao modo como a tarefa é vista, ou seja, ao ponto de vista do elaborador ou dos participantes.

Definimos tarefa nesta pesquisa com base nos critérios do Quadro 1: 
Quadro 1. Critérios definidores de tarefa nesta pesquisa (BARBIRATO, 2005):

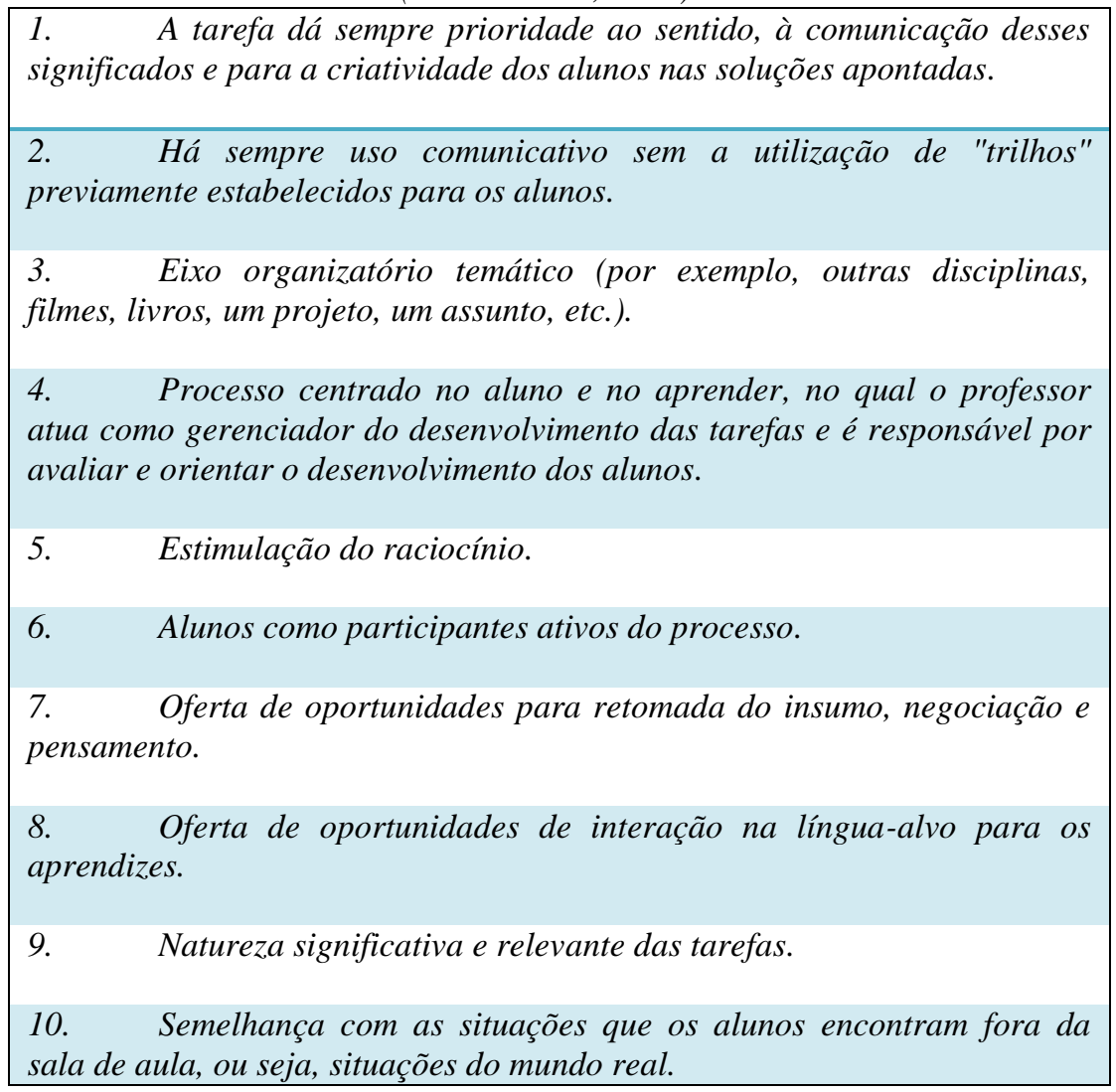

\subsection{A CLC na formação do professor}

Para estar apto a ensinar, é necessário que o professor possua uma série de requisitos básicos, incluindo-se competências específicas. No que se refere a essas competências, concordamos com Almeida Filho (2008) ao afirmar que a competência mais básica é a implícita, constituída de intuições, crenças e experiências. Se, aliada a essa, o professor possuir a CLC para operar em situações de uso da língua- 
alvo, ele já estará em condições de ensiná-la em um sentido básico ou tosco de ensinar.

Desse modo, acreditamos que para a formação de um professor seja necessário um conjunto de competências, e não apenas possuir a CLC. Contudo, neste estudo analisamos o desenvolvimento da CLC, pois quando o aluno não possui nem essa competência o ensino fica inviabilizado (ALMEIDA FILHO, 2008).

A tarefa de definir o construto de CLC em um contexto de ensino-aprendizagem de línguas estrangeiras apresenta-se de forma confusa em face do grande número de discussões teóricas que buscam abordar esse tema polêmico. Soma-se a isso o fato de o termo originalmente não provir de estudos na área da Linguística Aplicada, que envolve estudos de questões de uso da linguagem na prática social, muitas vezes nas salas de aula, como no caso da Teoria de Ensino e Aprendizagem de Línguas (ALMEIDA FILHO, 1993; 2008).

De fato, o construto de CLC tem sido relacionado com o construto de Competência Comunicativa (CC) amplamente discutido, adaptado, interpretado e explorado de acordo com as preocupações da Linguística Aplicada e da Pedagogia de Ensino de Línguas (WIDDOWSON, 1989). Compreendemos o conceito de CLC como sinônimo do conceito de CC, uma vez que engloba, em nossa compreensão, a junção da competência linguística, apontada nos modelos propostos como uma subcompetência da CC, e a capacidade de uso da língua em contextos sociais. De acordo com Bachman (1991, p. 682), a capacidade comunicativa pode ser definida como "capacidade para usar o conhecimento da língua em combinação com as características do contexto de uso linguístico para se criar e interpretar significados". 8

Concordamos com Almeida Filho (2008) que por meio do desenvolvimento da competência comunicativa o aluno desenvolve automaticamente a competência linguística, sem que o reverso seja necessariamente verdadeiro. Um aluno pode demonstrar competência linguística sem conseguir fazer uso comunicativo da língua. Uma subcompetência da competência linguística frequentemente trabalhada

8 "Communicative capacity is the capacity for using the knowledge of language in conjunction with the features of the language use context to create and interpret meaning." 


\section{O desenvolvimento da competência}

pelos professores em suas aulas é o conhecimento metalinguístico, ao passo que o conhecimento metacomunicativo é menos abordado.

Para Almeida Filho (2008), a CLC implica a junção dos conceitos de competência linguística (conhecimentos que o professor tem da gramática implícita e explícita) e de competência comunicativa (capacidade de uso da LE), possibilitando ao professor operar em situações de língua-alvo, ao enfocar a língua que se sabe e se pode usar.

Ducatti (2010) argumenta que o ponto fundamental de uma limitada CLC pode ser constatado nos resultados de pesquisas nas quais se verifica que, em muitos casos, os cursos de Letras, que deveriam ser os principais contextos de formação de professores proficientes de inglês, não vêm cumprindo seu papel satisfatoriamente (ALMEIDA FILHO, 1992; BAGHIN-SPINELLI, 2002; CONSOLO, 1996, 1997, TEIXEIRA DA SILVA, 2000; VIEIRA-ABRAHÃO, 1992, 1996), questão essa amplamente reconhecida e bastante discutida no meio acadêmico. Convergentemente com essa questão, julgamos este estudo relevante e potencialmente promissor no sentido de oferecer possíveis encaminhamentos de prática pedagógica no contexto de formação de professores. Na seção seguinte apresentamos a metodologia utilizada nesta investigação.

\section{Metodologia da pesquisa}

O cenário deste estudo foi uma sala de aula de língua inglesa com 15 alunos do curso de Letras noturno, cuja duração é quatro anos, de uma faculdade particular. Somente 15 alunos compunham a turma porque a outra parte da classe optou por cursar a disciplina de língua espanhola. Escolhemos essa turma porque, embora fossem alunos do terceiro ano do curso de Letras, observamos ${ }^{9}$ que não possuíam competência linguístico-comunicativa satisfatória para atuar como professores de língua inglesa.

A disciplina possuía carga horária de quatro aulas semanais com duração de cinquenta minutos cada, e todas foram utilizadas para a

\footnotetext{
${ }^{9}$ Foi aplicado logo no início do curso um teste cloze para confirmar o nível de proficiência dos participantes da pesquisa.
} 
aplicação do planejamento temático baseado em tarefas comunicativas com foco no sentido, compreendendo assim aproximadamente 150 horas/aula de curso-pesquisa. O tema do planejamento foi a história da Inglaterra, e o material didático utilizado foi elaborado por Barbirato (2005).

Para a obtenção do perfil dos alunos foi aplicado, ao início da disciplina investigada, um questionário aberto, cujo objetivo era a obtenção de dados referentes à formação em língua inglesa, à razão para cursar Letras, à experiência profissional e às expectativas e interesses com relação à disciplina. Neste estudo, a aplicação do referido questionário permitiu traçar o perfil dos alunos participantes e, consequentemente, adequar melhor o conteúdo conforme suas necessidades. Com o objetivo de preservar a face e manter a ética e a integridade, utilizamos pseudônimos para nos referir aos participantes da pesquisa.

Além de buscar confiabilidade para o estudo, um número maior de instrumentos foi utilizado para captar a voz dos participantes, visto que nosso intuito foi levantar o maior número de indicações possíveis de desenvolvimento da CLC nos participantes da pesquisa.

$\mathrm{Na}$ coleta de dados foram utilizados os seguintes instrumentos para a efetivação do estudo: a) teste cloze inicial e final; b) questionário aberto inicial e final; c) gravação das tarefas em áudio (oito horas de gravação) e transcrições, sendo 23 tarefas orais (de cinco participantes diferentes) de momentos diferentes do curso transcritas e analisadas, porém dado o escopo deste artigo não apresentamos aqui todas as transcrições; d) transcrições das produções escritas, das quais cinco foram utilizadas para serem contrastadas com as orais e analisadas na pesquisa (pois nosso objetivo principal era a competência comunicativa com foco na oralidade); e) quatro avaliações escritas bimestrais oficiais exigidas pela faculdade.

Com o intuito de nos orientarmos na análise dos dados, elaboramos algumas faixas de proficiência para os participantes objetivando avaliar seu nível na entrada e ao término do curso. Os níveis elaborados são: incipiente, inicial, regular e funcional, que serviram para analisar o desempenho dos alunos em todas as avaliações $^{10}$ aplicadas ao longo do curso. Entretanto, para nos

${ }^{10}$ Avaliações, testes e provas são utilizados como sinônimos nesta pesquisa. 


\section{O desenvolvimento da competência}

adequarmos ao sistema de avaliação vigente, no qual os resultados do desempenho dos alunos devem ser mensurados por uma escala numérica de 0 a 10, vimos a necessidade de converter esses conceitos em números.

Quadro 2. Conceitos de desenvolvimento da CLC

\begin{tabular}{|l|l|l|}
\hline Nota & Conceito & Fala palavras esparsas e desconectadas. \\
\hline $0,0-3,0$ & Incipiente & $\begin{array}{l}\text { Fala frases muito básicas sobre si ou sobre o } \\
\text { ambiente. }\end{array}$ \\
\hline $3,1-4,5$ & Inicial & $\begin{array}{l}\text { Consegue comunicar fatos e opiniões com frases } \\
\text { desconectadas e sem coesão textual. }\end{array}$ \\
\hline $4,6-8,0$ & Regular & $\begin{array}{l}\text { Consegue transmitir ideias de forma simples e } \\
\text { clara, sem, contudo, possuir fluência ou utilizar } \\
\text { construções elaboradas na linguagem falada ou } \\
\text { escrita. Consegue se comunicar de forma } \\
\text { inteligível na língua-alvo. }\end{array}$ \\
\hline
\end{tabular}

\section{Análise dos dados}

Neste item, analisamos as produções orais dos alunos em três momentos diferentes do curso, os quais denominamos: "momento 1", "momento 2" e "momento 3", correspondentes ao início, ao meio e ao final do curso, respectivamente.

Para tanto, demonstramos como os alunos utilizavam a línguaalvo no início do curso com relação à sua CLC; como falavam, com ou sem coesão, se usavam o português; se seus turnos eram curtos ou longos; se cometiam muitos erros quanto à forma; se seus enunciados faziam sentido, etc. Fizemos o mesmo para o meio do curso (momento 2) e para o final (momento 3) a fim de triangular os dados, explicando as reações dos participantes quanto a esse tipo de planejamento e suas percepções quanto à melhora de sua CLC por meio de autoavaliações. 


\subsection{Descrição das tarefas analisadas}

$\mathrm{Na}$ elaboração da primeira tarefa do momento 1 os participantes tiveram de dizer qual seria o monumento antigo que eles gostariam de visitar e por quê. Portanto, os critérios para a elaboração dessa tarefa foram expressar o desejo de visitar determinado monumento e depois justificar a escolha.

Para viabilizar a elaboração de tal tarefa foram mostradas aos alunos imagens em slides de PowerPoint das sete maravilhas do mundo antigo e das maravilhas do mundo moderno, acompanhadas de explicação na língua-alvo pela pesquisadora sobre um pouco da história que envolve esses monumentos, além de textos e pré-tarefas sobre esse assunto.

A tarefa analisada no momento 2 versava sobre o início da colonização da Grã-Bretanha, o final da era do gelo, os primeiros povos, como viviam e como eram. Os critérios para a elaboração da tarefa do momento 2 foram relatar o início da colonização da GrãBretanha e como foi formada quando se separou da Europa. Os alunos também deveriam falar sobre os primeiros habitantes, como eram, como sobreviviam, que tipo de cultura tinham, que monumentos construíram, relatar quais foram os povos que chegaram à Britânia e qual a cronologia deles até os viquingues.

Para viabilizar a elaboração da tarefa, foram fornecidas aos alunos explicações na língua-alvo pela pesquisadora na lousa e também por meio de mapas digitalizados, DVDs sobre a história da Grã-Bretanha, pré-tarefas escritas e orais com trabalho em pares.

Na sequência, para a elaboração de outra tarefa, como a do rei Henry VIII, proposta no momento 3 do curso, as explicações fornecidas pela professora sobre a tarefa foram na língua-alvo, acompanhadas de apresentações de slides no PowerPoint e trechos da série The Tudors, sendo sugerido pela pesquisadora aos alunos que assistissem às duas temporadas iniciais dessa série em casa, e alguns deles assim o fizeram. Também foram utilizadas pré-tarefas escritas e trabalho oral em pares.

Defendemos que o fato de os alunos terem recebido quantidade abundante de insumo relevante e diversificado foi fundamental para que produzissem na língua-alvo. 
Os critérios estabelecidos para a elaboração da tarefa do momento 3 foram: falar sobre o rei Henry VIII, sua vida amorosa, sua primeira esposa, Catherine of Aragon, sobre sua importância, sobre as sucessivas esposas que o rei teve (pelo menos duas delas, pois a segunda temporada da série termina com a execução de Anne Boleyn), sobre o motivo de seus vários casamentos, sobre os filhos que teve ao longo de sua vida e sobre as circunstâncias em que se separou das esposas.

Depois de relatarmos os critérios estabelecidos para a elaboração das tarefas, apresentamos a análise dos três momentos de dois dos alunos participantes da pesquisa, que foram escolhidos com base em seu desempenho no pré-teste (teste cloze inicial). Portanto, procuramos escolher duas participantes com nível de desempenho incipiente, ressaltando que nesse conceito de desenvolvimento as notas variam de 0,0 a 3,0, demonstrando que seus níveis de progresso no desempenho da CLC variaram proporcional e diferentemente, em conformidade com suas diferenças individuais. Optamos por duas participantes com desempenho incipiente por se tratar do maior número de participantes do contexto que trabalhamos.

\subsection{Análise da CLC em três momentos}

$\mathrm{Na}$ sequência, analisamos as produções das tarefas orais dos três momentos do curso da participante Poliana, que se destacou sobremaneira quanto à sua capacidade de comunicação na língua-alvo, pois, ao realizar o teste cloze inicial, obteve o conceito "incipiente", tendo melhorado bastante ao longo do curso (Quadro 3).

Poliana teve dificuldades no início do curso, mas, ao perceber que se fazer entender não era impossível, seguiu todas as instruções da pesquisadora, não faltava às aulas e teve uma postura participativa, engajando-se em todas as atividades propostas. Também seguia as orientações para realizar as pré-tarefas e as tarefas, participando ativamente das interações em pares, que geralmente ocorriam com a participante Amanda, o que era bastante produtivo para Poliana e fazia com que se sentisse segura para desempenhar a tarefa oral posteriormente para a Pesquisadora e para a classe. 
Quadro 3. Análise da CLC de Poliana

nas produções orais em três momentos do curso

\begin{tabular}{|c|c|}
\hline Mom. & Transcrições \\
\hline 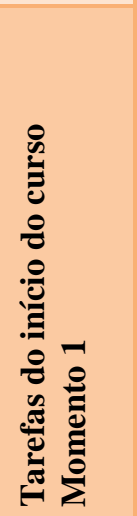 & $\begin{array}{l}\text { I would visit Taj Mahal in India because(...) ahn (...) there is a love } \\
\text { story behind it (..) that construction ahn (...) and I'm very } \\
\text { romantic, I like love stories and I believe is interesting construction } \\
\text { and a very ellegant too. } \\
\text { I would like to visit Stonehenge (...) is a great monument of history } \\
\text { of word, and it has many mistery that envolve it (...) ahn (...) I (...) } \\
\text { believe that Stonehenge was.built by several peoples each one gave } \\
\text { his contribution (...) ahn (...) the Iberians, the Celts, the Druids, } \\
\text { each one gave his contribution... I think the purpose of Stonehenge } \\
\text { is a place to worship gods, I don't know (..) Stonehenge has many } \\
\text { energy and (...) ahn (...) this (...) can envolve us (...) only. }\end{array}$ \\
\hline 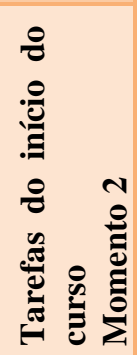 & $\begin{array}{l}\text { First the Britain was part of European Continent after the ice age, } \\
\text { it separated from Europe(...) ahn (...) the first (...) inhabitants that } \\
\text { were in Britain were the Iberians. The Iberians build the } \\
\text { Stonehenge. After the Iberians, the Celts came: to Britain. The Celts } \\
\text { were more advanced the Iberians (...) ahn, after the Celts there } \\
\text { were Roman invasion (...) Roman invasion. The Romans } \\
\text { introduction the cristianismo in their culture, their language, their } \\
\text { customers, and after Romans the Angle-Saxons arrived there. }\end{array}$ \\
\hline 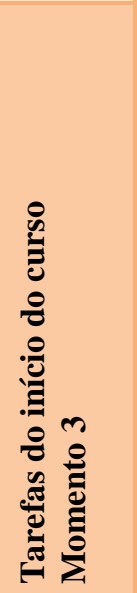 & $\begin{array}{l}\text { Henry the VIII was the second king of a dynasty ahn(...) he married } \\
\text { with Catherine of Aragon ahn (...) she was six years older than } \\
\text { Henry (..) ahn (...)Catherine had (...) six stillbirths and after she } \\
\text { had a child ahn called Mary (...) Bloody Mary ahn (...) Henry and } \\
\text { Catherine had ahn (...) different viewpoints of the future of Mary } \\
\text { ahn Henry wanted a son to pass his kingdom (...) and not a } \\
\text { daughter with problems as Mary (..) ahn (..) Catherine was } \\
\text { daughter of a (...) a Queen of Spain and her (..) her mother was a } \\
\text { crusader? crusader ahn (..) the Catherine (..)ahn(.) herself was } \\
\text { born in a campaign of the mother(..) rsrs (...) I don't know (...) ahn } \\
\text { Catherine ahn(..) Henry and Catherine ahn(...) separated because } \\
\text { Henry wanted a son with other woman, né? And (...) ahn (...) so, } \\
\text { they (...) they separated and Henry get married with Anne Boleyn } \\
\text { (...) and Henry ahn (...) instituted Protestantism. That's it. }\end{array}$ \\
\hline
\end{tabular}


Analisando as tarefas orais de Poliana do momento 1 do curso no quadro anterior, observamos que ela não utilizou construções soltas, mas frases bem elaboradas, expressando suas ideias sobre o assunto estudado, explicando que tem preferência por visitar o Taj Mahal por ser um local romântico, envolto em uma história de amor, e cumprindo os critérios estabelecidos para a elaboração da tarefa.

Concordamos com Vygotsky (2000, p. 88), citado na fundamentação teórica deste estudo, quando o autor considera que o aprendizado de uma língua por meio da interação possibilita que os aprendizes troquem conhecimentos entre si e debatam ideias e opiniões sobre as atividades propostas em grupos ou pares, podendo, pois, prepará-los para agir com autonomia em situações futuras semelhantes àquelas enfrentadas nos momentos de aprendizagem. Esse autor também destaca o fato de toda pessoa poder fazer mais se tiver o auxílio de outra. Nessa perspectiva, o que o aprendiz é capaz de fazer em cooperação com alguém hoje será capaz de fazer sozinho amanhã.

Afirmamos, com base em dados empíricos apresentados até o momento, que não há como a pessoa dominar a linguagem (o mundo à sua volta) sem a ajuda de alguém. A aprendizagem acontece por meio da interação de pessoas de diferentes níveis sociais, habilidades e conhecimentos.

Analisando os dados coletados, observamos que o par mais competente representa uma espécie de andaime para o outro, que pode servir de base até que o menos experiente tenha domínio do conteúdo. Pudemos observar na relação de Amanda e Poliana a importância da interação do trabalho em pares na aquisição de LE.

Com base nos dados coletados e analisados, defendemos que o ensino por meio de tarefas comunicativas problematizadoras gera interação dos alunos e consequente negociação de significados, o que ajuda a finalizar a tarefa de forma bem-sucedida.

Quanto aos erros de Poliana, queremos salientar que estes ${ }^{11}$ foram de base estrutural no momento 1 do curso, como o uso do artigo indefinido em local inadequado em "... and a very ellegant too" (linha 3), quando deveria ser "...and very ellegant too", e a falta do artigo indefinido na construção "...believe is interesting", quando deveria ser “...believe is an interesting..." (linha 3 ).

\footnotetext{
${ }^{11}$ Nesta pesquisa não fazemos distinção entre os termos erro e lapso.
} 
Ainda nesse mesmo excerto (linha 3), além de um artigo a mais e um artigo a menos, houve também a não colocação do pronome it. Acreditamos que a ocorrência desses erros se deve à LM dos participantes de pesquisa, visto que essa não requer esse tipo de construção nas orações. Porém, neste estudo não focaremos a interferência da LM, pois seria assunto adequado para outro estudo ou nova pesquisa.

Outra dificuldade apresentada por Poliana foi não conseguir utilizar conectores para construir as orações na língua-alvo, como no excerto "I would like to visit Stonehenge (...) is a great monument..." (linha 4). Também podemos observar o uso incorreto de many - usado antes de substantivos contáveis -, que foi posicionado na oração antes de substantivo incontável (linhas 8 e 9): "Stonehenge has many energy..." (deveria ser "Stonehenge has much energy...").

Verificamos nas linhas 1 e 2 do momento 2, no excerto "First the Britain was part of European Continent after the ice age it separated from Europe", que a aluna produziu um segmento longo, sem pausas ${ }^{12}$ e quase sem erros gramaticais ou estruturais, o que consideramos um avanço com relação às frases fragmentadas do momento 1.

A participante cumpriu os critérios estabelecidos para a realização dessa tarefa, falando sobre as invasões na ordem correta, apenas se esquecendo de mencionar os vikings.

$\mathrm{Na}$ tarefa do momento 3 do curso, também citada no quadro anterior, Poliana mostra-se confiante e constrói um segmento longo, carregado de significado: "Henry the VIII was the second king of a

\footnotetext{
12 Pausas: entre os vários elementos possíveis relacionados ao conceito de fluência estão as pausas preenchidas. Elas se diferenciam das pausas silenciosas porque o falante preenche o tempo com sons que não configuram itens lexicalizados. As pausas preenchidas são vistas como sinalizadores de hesitação por Merlo (2006), Moniz (2006), Scarpa (1995) e Marcuschi (1999), podem ser consideradas fluentes ou hesitativas, dependendo de sua localização sintática e/ou prosódica, e não se encontram aleatoriamente distribuídas (MARCUSCHI, 1996; , BORGES-ALMEIDA, 2009). (As pausas são um assunto muito relevante, mas não são exploradas neste texto dissertativo; todavia, consideramos que servem de tópico para um novo estudo.)
} 
dynasty ahn(...) he married with Catherine of Aragon ahn (...) she was six years older than Henry...", cumprindo o critério estabelecido, que era falar sobre o rei Henry VIII. Embora o excerto contenha algumas pausas, acreditamos que estas foram feitas com a intenção de manter o turno da conversa, mostrando à $\mathrm{Pp}$ e aos colegas que ela pretendia continuar o relato.

Poliana mostrou-se segura quanto ao tema, como podemos observar no excerto: "Henry and Catherine had (...) ahn (...) different viewpoints of the future of Mary (...) ahn (... ) Henry wanted a son to pass his kingdom (...) and not a daughter with problems as Mary...", e, apesar de não utilizar muitos conectores e cometer erros estruturais e hesitações, acreditamos que seu discurso melhorou consideravelmente em relação ao momento 1 . Novamente os critérios para a elaboração bem-sucedida da tarefa foram cumpridos.

Observamos nas respostas de Poliana ao questionário aplicado na metade do curso que a aluna sente-se motivada com o curso e acredita que está melhorando:

[...] acho que meu inglês melhorou porque comecei a pensar mais em inglês e buscar mais os significados das palavras. (Poliana)

A participante alega que sente mais vontade de estudar e de procurar significados de palavras que desconhece, e acreditamos que esse seja um sinal de grande motivação para a aquisição da línguaalvo.

Para complementarmos esta análise, transcrevemos as respostas da participante quando lhe pedimos que fizesse sua autoavaliação e a avaliação do curso.

Acredito que a quantidade de informação que recebemos e o fato de tratar de um assunto importante para nós é que fez com que conseguíssemos falar, e também os trabalhos em pares e em grupos ajudaram muito, bem como tudo o que aprendemos nos anos anteriores na faculdade.

Poliana ressalta o fato de o conteúdo temático do curso ter sido importante para seu sucesso e o dos colegas. Isso se deve ao fato de 
termos optado por utilizar um tema relevante para o público-alvo, fazendo com que se sentissem motivados para prosseguir e se empenhar.

Neste estudo defendemos ser muito producente para o aluno adquirir uma nova língua em um contexto rico com insumo real. Conforme já afirmamos na fundamentação teórica deste estudo, o foco está no sentido, porém há atenção secundária à forma sempre que necessário. O insumo abundante e diversificado é muito importante, mas há outros fatores, como interação, motivação, o papel do professor (que em alguns momentos fala mais devagar, repete, sistematiza, etc.) e as próprias tarefas problematizadoras, que influenciam o processo de aquisição da língua-alvo.

A participante enaltece o trabalho em pares, admitindo que ter sido este um fator preponderante para seu processo de aquisição da LE.

Na sequência está a avaliação do curso feita pela participante em questão.

Poliana (avaliação do curso): $O$ curso é bom porque nos incentiva a usar a língua inglesa em situações extraclasse, para coisas de verdade, como aprender sobre a história de um país, a ter a consciência de que podemos e devemos aprender sempre mais. Nosso campo de aprendizagem e ação não pode ser restrito, a língua inglesa precisa fazer parte do nosso dia a dia.

[...] nas tasks fazemos coisas do dia a dia, como argumentar, emitir opiniões sobre pessoas, coisas, situações, contar casos, histórias, escolher, etc. [...]

A participante ressalta em sua avaliação do curso novamente o fato de o tema ser relevante para os alunos de Letras e ser um assunto real, o que, de acordo com Almeida Filho (2003), tem importância para a criação de ambiente comunicativo voltado para a aquisição.

A análise seguinte refere-se à aluna Roberta, que foi classificada com conceito "incipiente" no início do curso e obteve desenvolvimento de CLC em todas as atividades realizadas durante o curso, tanto escritas quanto orais. 
Quadro 4. Análise da CLC de Roberta

nas produções orais em três momentos do curso

\begin{tabular}{|c|c|}
\hline Mom. & Transcrições das tarefas orais \\
\hline 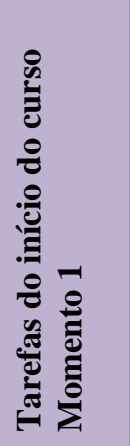 & $\begin{array}{l}\text { I would like to visit Taj Mahal in India because there is a love story } \\
\text { before (...) ahn (...) behind the mausuleum. } \\
\text { I would like to visit Stonehenge because (...) I like the places that } \\
\text { has (...) ahn (...) misteries, I think it is curious (...) ahn (...) I think } \\
\text { the Stonehenge was build to worship some god or something. I think } \\
\text { the Iberians start building the Stonehenge but I think there were } \\
\text { peoples before (...) ahn (..) I think the purpose of Stonehenge was } \\
\text { to remember the story of England. }\end{array}$ \\
\hline 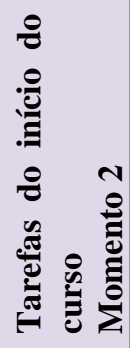 & $\begin{array}{l}\text { The Britain was part of the Continent of Europe, then channel, the } \\
\text { English channel flooded, the first inhabitants of the Britain were the } \\
\text { Iberians, the Iberians was the dark-haired, hunter, fishermen, then } \\
\text { the Celts came to Britain (...) then the Romans came to Britain (...) } \\
\text { Julius Cesar made a expedition twice to Britain (...) Claudius made } \\
\text { an unsuccessful expedition and then come to Britain the Angle- } \\
\text { Saxons. }\end{array}$ \\
\hline 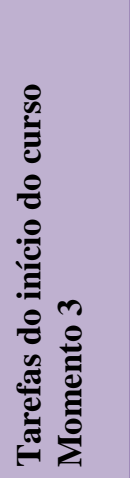 & $\begin{array}{l}\text { Catherine was the first wife of Henry the VIII and she was six years } \\
\text { older than he (...) ahn (..) she ahn had six (...) stillbirths but she } \\
\text { could give him a daughter (...) Mary (..) ahn (...) and (...)ahn (.) } \\
\text { Henry and Catherine had (..)ahn (...)different viewpoints about (..) } \\
\text { ahn (...) her future and Henry (...)ahn (...)didn't (..)ahn (...)like } \\
\text { Mary because he want a son to pass your kingdom (...)but } \\
\text { Catherine was (...)Isabel's daughter and she was a (..)ahn } \\
\text { (...)Queen of Spain (..) and she was a crusader and Mary could be } \\
\text { a queen (..) ahn(...) but Henry ahn (...) he want a son but Catherine } \\
\text { couldn't be a mother so Henry divorced Catherine and married to } \\
\text { Anne Boleyn. }\end{array}$ \\
\hline
\end{tabular}

No início do curso, Roberta mostrou-se interessada e participativa, dizia que gostava muito da língua inglesa e sentia vontade de melhorar sua pronúncia. Observamos sua determinação em 
melhorar seu desempenho oral quando a participante expressa seu ponto de vista no excerto a seguir:

[...] decidi fazer as coisas que a professora pedia para fazer em casa, estudar a história, assistir a filmes e séries da história da Grã-Bretanha, assistir a filmes com legendas em inglês [...]. (Roberta)

A aluna possuía atitude favorável à aquisição da língua-alvo desde o início do curso, pois gostava da língua e estava disposta a esforçar-se para adquiri-la. Manteve-se com o filtro afetivo baixo e a autoestima elevada.

Podemos observar que suas produções orais iniciais eram coerentes, com sentenças bem estruturadas, porém cometia erros de preposição em profusão, conforme revelam as linhas 1 e 2: "there is a love story before (...) ahn (...) behind...".

Roberta também cometeu erros de tempos verbais básicos e concordância nas orações, como se observa no excerto a seguir: " “.. I like the places that has (...) ahn ...", em vez de "... places that have ..." (linha 3).

Outra situação percebida nas transcrições foi a tentativa de uso da voz passiva na linha 4: "Stonehenge was build to worship some god...", utilizando “...was build..." em vez de “...was built...”, que seria a forma correta do particípio passado do verbo to build.

Sabemos que a competência linguística considerada necessária ao desenvolvimento da competência comunicativa (ALMEIDA FILHO, 2008/2008; SAVIGNON, 2001) envolve o conhecimento das regras de funcionamento da língua, que devem ser abordadas nas aulas de LE.

No entanto, de acordo com os pressupostos teóricos do PTBT, que têm como base o ensino comunicativo, a gramática não deve ser o foco do processo de ensino e aprendizagem, deve ser evidenciada em situações autênticas de comunicação que determinem alguma estrutura linguística durante a interação e demandem sua sistematização, tornando o uso da forma da língua significativa.

Baseamo-nos também na opinião de Willis e Willis (2007), que se mostram contra o foco em estruturas específicas antes de os 
alunos se envolverem com uma tarefa. Em contrapartida, são a favor de abordá-las ao final de uma sequência de tarefas.

Concordamos com os autores citados e defendemos que as estruturas incorretas das produções dos alunos devem ser corrigidas no estágio das pós-tarefas. Deve ocorrer uma sistematização do item linguístico apenas se a dúvida não for manifestada pelo aluno durante a elaboração da tarefa e a sistematização for justificada.

Nas produções orais do momento 1 , Roberta cometia vários erros de preposição, o que não ocorreu nas produções do momento 2 . Também os usos equivocados de tempos verbais do momento 1 desapareceram. Consideramos que Roberta apresentou desenvolvimento considerável na produção oral do momento 2 do curso.

A aluna assim expressa seu progresso:

No início do curso havia um certo medo por parte dos alunos de trabalhar com as tasks. Porém, conforme o tempo passava, os alunos ficavam motivados e seguros com esse trabalho. Eu acho que isso foi um diferencial para nossa turma, pois nos desenvolvemos de tal maneira que talvez não tivéssemos conseguido se fosse uma aula normal. Acho que melhorei muito.

Nas linhas 1 e 2 da tarefa do momento 2, a aluna tenta manter o turno e sinalizar que continuará a fala por repetição de palavra: “...then channel, the English channel flooded...", o que revela maior segurança por parte dela ao falar.

Os erros cometidos no excerto do momento 2 foram: a utilização do artigo definido the na linha 1 em "the Britain"; a construção "the Continent of Europe" ainda na linha 1, em vez de "European Continent", usando-se um adjetivo antes do substantivo, o que também pode ser entendido não como um erro, mas como uma opção linguística menos adequada; a concordância verbal em "Iberians was the dark-haired hunters..." na linha 3, que deveria ser "Iberians were dark-haired hunters...", e ainda na mesma linha a utilização equivocada do artigo the antes de dark-haired, que é um adjetivo e deveria estar precedendo um substantivo; o indefinido $a$ antes de expedition em "Julius Cesar made a expedition twice", sendo 
expedition uma palavra que inicia com som de vogal e que deve ser precedida por an; e a inversão da ordem dos elementos na sentença "... and then come to Britain the Angle-Saxons...", que deveria ser “... and then the Angle-Saxons came to Britain...", além do uso incorreto do tempo verbal Simple Present "come” em vez do Simple Past "came".

As produções de Roberta no momento 3 demonstram segurança e autoestima elevada, domínio do conteúdo e motivação ao comunicar-se, como corrobora este excerto: "Catherine was the first wife of Henry the VIII and she was six years older than he (...) ahn (...) she ahn had six (...) stillbirths but she could give him a daughter (...) Mary (...)”. Apesar de algumas pausas no discurso, a participante mostrou ter domínio do vocabulário necessário e das estruturas gramaticais, transmitindo a mensagem de forma satisfatória.

A observação da autoestima elevada de Roberta e de sua motivação nos leva a concordar com Krashen (1997), quando salienta que a autoestima é também um fator interno preponderante na aprendizagem de línguas. Como observa Lago (2000), a autoestima vincula, entre outros, fatores como inibição, extroversão, empatia, ansiedade, atitudes, egocentrismo. Todas essas afetividades podem contribuir para o sucesso ou o fracasso do aprendiz. No caso de Roberta, suas atitudes tiveram um papel positivo, favorecendo a aquisição da língua-alvo.

Podemos observar, pela sua autoavaliação e pela avaliação que fez do curso, que ela se beneficiou com o PTBT, conseguindo enxergar também o progresso dos colegas.

Roberta (autoavaliação): Hoje consigo ler e entender melhor o inglês. Posso falar, claro que com limitações, mas consigo me comunicar graças a este ensino. Acredito até que a forma de enxergar o inglês mudou muito e também passei a entender a história da Inglaterra. A comunicação constante entre os alunos é importante, acredito que todos ou a maioria dos alunos teve melhora significativa em seu inglês.

A participante considera que sua CLC melhorou graças ao PTBT e que o tema da história da Grã-Bretanha colaborou para 
aumentar sua motivação e estabelecer comunicação constante entre os participantes.

Roberta (avaliação do curso): Acredito que todos os alunos tiveram uma boa evolução no curso. Foi muito importante a interação com os colegas para assim aprendermos juntos. Cada um possui sua dificuldade, mas com este ensino diferenciado todos nós pudemos melhorar razoavelmente na língua inglesa.

Em sua avaliação do curso, Roberta ressalta que as oportunidades de interação proporcionadas por esse tipo de ensino fizeram com que os alunos aprendessem juntos, e cada um pôde melhorar de acordo com seu comprometimento.

A análise a seguir é referente a uma participante que foi relutante desde o início do planejamento. Heloísa foi classificada como "incipiente" no teste cloze inicial porque deixou 19 das vinte lacunas do teste em branco, o que mostra sua atitude negativa desde o início. Por não querer errar, ela sequer tentava se comunicar na língua-alvo (Quadro 5).

Entre os 15 alunos da sala de aula, Heloísa foi uma dos que menos se envolveram com as aulas, mantendo essa postura durante quase todo o curso. Em todas as atividades propostas, seu filtro afetivo era alto, fator que prejudica a aprendizagem de uma nova língua, segundo Krashen (1997).

Desde a elaboração da primeira tarefa, esta participante da pesquisa procurava ficar por último na esperança de não sobrar tempo para sua produção oral ocorrer, e ela só produzia depois que a pesquisadora utilizava muitos argumentos para persuadi-la.

Concordamos com Ellis (2003) quando argumenta que as crenças dos aprendizes e seus estados afetivos estão propensos a exercer um efeito direto na aquisição de L2/LE. Todavia, suas próprias crenças e estados afetivos podem ser influenciados por uma série de fatores gerais relacionados às suas habilidades e desejo de aprender, bem como à forma como eles optam por fazer isso. 
Quadro 5. Análise da CLC de Heloísa

nas produções orais em três momentos do curso

\begin{tabular}{|c|c|}
\hline Mom. & Transcrições das tarefas orais \\
\hline 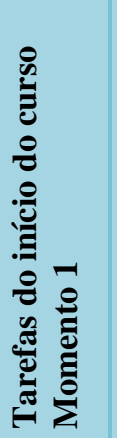 & $\begin{array}{l}\text { I would visit Collision because the archi (...) architect (...) ture (...) } \\
\text { is very good, is very beautiful and it is historical important too. } \\
\text { I would like to visit Stonehenge because it is interesting place (...) } \\
\text { and (...) it was build as a calendar or a clock. It was build by the } \\
\text { Iberians. } \\
\text { Pp. Would you like to visit Stonehenge? } \\
\text { Pp. Would you like to go there, to see (Pp. faz gesto apontando para } \\
\text { os olhos) Stonehenge? } \\
\text { Heloísa: Sim, eu gostaria. }\end{array}$ \\
\hline 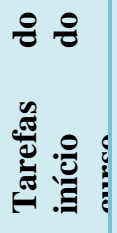 & $\begin{array}{l}\text { The first (...) ahn (...) inhabitants to Britain (...) ahn (...) in to } \\
\text { Iberians (..) the year and construction Stonehenge, after the Celts } \\
\text { come from (...) ahn (...) to Britain (...) ahn (...) after (...) rsrs (...) } \\
\text { Romans come from Britain. }\end{array}$ \\
\hline 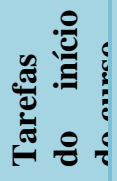 & A aluna não realizou as tarefas do momento 3. \\
\hline
\end{tabular}

Heloísa geralmente fazia as tarefas na aula seguinte, depois de ter tido tempo de prepará-las em casa, e mesmo assim mostrava muita hesitação na elaboração, sua fala era truncada e incorreta. Também não construía uma frase completa utilizando a estrutura básica da línguaalvo em questão: sujeito + verbo + objeto. Não flexionava os verbos nos tempos adequados e apresentava dificuldade na utilização de preposições.

Mesmo diante da enorme relutância de Heloísa, é possível verificar nas transcrições que ela compreendia o que a pesquisadora falava na língua-alvo, pois interagia respondendo na língua materna.

Heloísa não realizou o mesmo número de tarefas que os outros participantes da pesquisa porque faltava demais, e quando estava presente não participava ativamente. Seu comportamento indicava que 


\section{O desenvolvimento da competência}

não possuía motivação intrínseca para a realização das tarefas. Durante as aulas, não se esforçava para realizar as pré-tarefas e participar das interações em duplas ou em grupos que antecediam a produção oral da tarefa principal, apenas dizia que não conseguiria, não queria, não sabia e não tinha tempo para estudar.

Observando as transcrições de Heloísa, notamos que em relação ao momento 1 sua produção oral diminuiu no momento 2 e que as pausas foram utilizadas com mais frequência. É possível verificar já na primeira oração de sua produção - "The first (...) ahn (...) inhabitants to Britain (...) ahn (...) in to Iberians (...) the..." - que ela se serviu de palavras esparsas, sem conectá-las a um verbo.

Heloísa ainda manteve seu filtro afetivo alto, o que talvez tenha impedido seu desenvolvimento no momento 2 do curso. $\mathrm{O}$ filtro afetivo está relacionado com a afetividade do aluno e dificulta a aprendizagem quando é elevado. Porém, alguns fatores podem aumentar a impermeabilidade do filtro afetivo, tais como: ansiedade, timidez, cansaço, motivação insuficiente e falta de identificação cultural com a língua-alvo.

No caso dessa participante, somava-se ao filtro afetivo alto a falta de motivação e a vergonha de cometer erros perante os colegas e a professora.

Segundo os estudos de Krashen (1997), pessoas que tendem à introversão, à falta de autoconfiança ou ao perfeccionismo podem desenvolver um bloqueio, comprometendo a espontaneidade devido à consciência da alta probabilidade de cometerem erros. No caso de Heloísa, o fator comprometedor pode ter sido o perfeccionismo, pois ela se recusava a falar por não querer errar e ser alvo de críticas.

Assim, concluímos que a experiência que tivemos com Heloísa foi muito rica para esta pesquisadora, pois, além de contribuir para nosso crescimento como pesquisadora, contribuiu para o cenário de professores de línguas, chamando a atenção para a importância do filtro afetivo e de outras atitudes e variáveis afetivas no aprendizado de uma nova língua.

Asseveramos que a capacidade de aprender uma LE depende também de fatores internos, como afetividade, filtro afetivo, autoestima e ainda de fatores externos, advindos da cultura de aprender que os alunos adquirem e carregam ao longo de toda a sua experiência intelectual, cultural e social. 
No decorrer do curso, Heloísa percebeu que a diferença entre ela e os outros participantes aumentava no que tange à produção da oralidade, o que pode ter causado constrangimento e feito com que a aluna sentisse ainda menos vontade de se manifestar.

Lago (2000) considera que a autoestima é primordial no processo, uma vez que, quando elevada, se converte em segurança, encorajando e fornecendo ao aluno subsídios para desenvolver tarefas ainda mais difíceis. Entretanto, se ocorrer o contrário, o aluno diminuirá seu empenho, transformando o que era aprendizagem em atividade frustrante.

Heloísa (autoavaliação): Com o passar do tempo, percebi que eu precisava praticar o inglês para poder aprendê-lo. Com as aulas sobre a história da Inglaterra fui praticando devagar algumas frases e consegui perder um pouco do medo e da insegurança. Percebi que com esse método é possível superar as dificuldades e aprender uma nova lingua.

Podemos observar pela fala de Heloísa que ela admite que, se tivesse participado o quanto deveria do curso, teria aprendido mais e esse tipo de ensino a teria ajudado. Contudo, devemos considerar que para certas pessoas as situações de exposição, tomadas de decisões e riscos são difíceis e requerem maior tempo de adaptação. De qualquer forma, consideramos que a experiência com a participante foi producente, pois ela conseguiu perceber que esse tipo de ensino pode beneficiá-la, e talvez em outra oportunidade essa experiência possa ajudá-la a superar suas inseguranças e inibições.

Heloísa (avaliação do curso): Ao iniciarmos o curso, percebi que não era só eu que tinha dificuldades com o novo método, pois somos alunos acostumados a ser sempre passivos, e essa nova postura de ter que produzir (ativa) nos causava muitas inseguranças. Porém, evoluímos bem, perdemos os medos, a aprendizagem do conteúdo melhorou e, o mais importante, soltamos mais a língua, começamos a nos comunicar melhor, a ter mais vocabulário. 
Heloísa percebeu que a maioria dos participantes de seu grupo melhorou bastante e até se inclui no comentário quando diz "perdemos os medos...", “... soltamos mais a língua...” etc. Às vezes o aluno não evolui como gostaríamos, mas ele pode ter rompido barreiras antes intransponíveis, e a experiência pode reverter-se em fator de grande importância em sua vida acadêmica.

Concluímos com este estudo que a análise dos fatores internos e externos dos alunos nas aulas de línguas pode levar à compreensão do motivo de a aquisição/aprendizagem destes acontecer em níveis tão distintos e específicos, além de promover uma autorreflexão do professor em exercício, instigando-o a criar estratégias que viabilizem o sucesso da aprendizagem e ter em mente que um dos pressupostos do ensino comunicativo é tornar o aluno autônomo nesse processo.

\section{Considerações finais}

Estamos cientes de que o ensino baseado em tarefas toma como foco primário o sentido em vez da forma. No entanto, reconhecemos que esse foco primário não inviabiliza uma atenção secundária à forma, subordinando-a ao uso da língua. Uma das críticas mais comumente dirigidas ao ensino baseado em tarefas refere-se à falta de desenvolvimento da competência gramatical, causando assim uma comunicação precária para os aprendizes. Essa foi a principal motivação para esta pesquisa, e após analisar os dados pudemos reconhecer traços positivos de desenvolvimento da competência linguístico-comunicativa nos participantes da pesquisa.

Os dados apurados nos revelaram indicativos de melhora na CLC das participantes Polyana e Roberta, que começaram o curso no nível incipiente de conhecimento da língua inglesa, mostrando assim um resultado promissor e positivo para o uso do ensino temático baseado em tarefas.

Uma possível justificativa para o não desenvolvimento da participante Heloísa podem ser seu alto filtro afetivo, sua falta de motivação e seu pouco envolvimento no curso. Poderíamos até mesmo arriscar que ela tem um perfil voltado para uma abordagem mais estruturalista e controlada, com menos exposição, mas isso é apenas uma suposição. 
O aspecto animador a ser reconhecido nesses dados é a possibilidade de desenvolvimento da CLC no ensino baseado em tarefas, possibilidade esta vislumbrada para o contexto de formação de professores, fundamental para todo o trabalho de ensino de LE, pois é nele que se formam aqueles que serão disseminadores de conhecimento na LE em outros vários cenários, como, por exemplo, a educação básica fundamental e média pública.

Além disso, o curso temático baseado em tarefas comunicativas propiciou aos alunos mais oportunidades de contato com a língua-alvo, tanto por meio da interação com os colegas, como na realização de atividades em equipe, ou pelo contato com a professora pesquisadora, que lhes oferecia constantemente insumos na nova língua. A proposta parece ter sido bastante satisfatória, pois mostrou aos alunos a nova língua de forma viva, como instrumento de comunicação em uso corrente na sala de aula e baseada em um assunto que lhes foi útil em outras disciplinas do currículo do curso de Letras, como Literatura Inglesa e Norte-Americana.

\section{Referências}

ALMEIDA FILHO, José C. P. O professor de língua estrangeira sabe a língua que ensina? A questão da instrumentalização linguística. Contexturas, v. 1, p. 77-85, 1992.

- Dimensões comunicativas no ensino de línguas. 5. ed. Campinas: Pontes, 2008.

BACHMAN, Lyle F. What does language testing have to offer? TESOL Quarterly, v. 25, n. 4, 1991.

BAGHIN-SPINELLI, Débora. C. M. Ser professor (brasileiro) de língua inglesa: um estudo dos processos identitários nas práticas de ensino. 2002. Tese (Doutorado em Linguística Aplicada) - Instituto de Estudos da Linguagem, Universidade Estadual de Campinas, Campinas, 2002. 
BARBIRATO. Rita C. A tarefa como ambiente para aprender LE. Dissertação (Mestrado em Linguística Aplicada) - Instituto de Estudos da Linguagem, Universidade Estadual de Campinas, Campinas, 1999.

BARBIRATO. Rita C. Tarefas geradoras de insumo e qualidade interativa na construção do processo de aprender LE em contexto inicial adverso. 2005. Tese (Doutorado em Linguística Aplicada) Instituto de Estudos da Linguagem, Universidade Estadual de Campinas, Campinas, 2005.

BORGES-ALMEIDA, Vanessa. Pausas preenchidas e domínios prosódicos: evidências para a validação do descritor fluência em um teste de proficiência oral em língua estrangeira. $A L F A$, v.53, n. 1, p. 167-193, 2009.

CANDLIN, Christopher. N. Towards task-based language learning. In: CANDLIN Christopher. N.; MURPHY. Dermot. (Eds). Language learning tasks. Lancaster Practical Papers in English Language Education, v. 7. Englewood Cliffs, New Jersey: Prentice Hall.1987.

CONSOLO, Douglas A. Classroom discourse in language teaching: a study of oral interaction in EFL lessons in Brazil. Unpublished $\mathrm{PhD}$ thesis. CALS, The University of Reading, UK, 1996.

- Investigando a linguagem e a interação professor-aluno na aula de inglês como língua estrangeira. Intercâmbio, v. 6, p. 520-540, 1997.

- The ability for communicative language use: an overview. Revista de . Letras, PUC, Campinas, v. 18, n. 1-2 p. 82 - 91. 1999.

CHOMSKY, Noam. Knowledge of language, its nature, origin and use. New York: Praeger, 1986.

CRANDALL, Joann. A. Content-centered language learning. ERIC Digest ED 367142. Washington, DC: Center for Applied Linguistics. (1994). 
CRANDALL, Joann. Language teacher education. Annual Review of Applied Linguistics, v. 20, p. 34-55, 2000

DUCATTI, Ana L. F. A interação verbal na língua-alvo e a proficiência oral na prática de sala de aula: (re)definindo o perfil de uma professora de língua inglesa da escola pública. 2010. Dissertação (Mestrado em Linguística Aplicada) - Instituto de Biociências, Letras e Ciências Exatas, UNESP, São José do Rio Preto, 2010.

ELLIS, Rod. Task-based language learning and teaching. Oxford: Oxford University Press, 2003.

HARLEY, Birgit. Patterns of second language development in french immersion. Journal of French Language Studies, v. 2, n. 2, p. 159-183, 1992.

KRASHEN, STEPHEN. Principles and practice in second language acquisition. Prentice Hall International. 1997.

LAGO, S. N. A do. Explorando a auto-estima na aquisição de segunda língua.In: MELLO, Heliana. A. B; DALACORTE, Maria. C. F. (Orgs.). A sala de aula de língua estrangeira. Goiânia: Editora UFG, 2000. p.83-100.

LONG, Michael; ROBINSON, Peter. Focus on form: theory, research and practice. In: DOUGHTY, Catherine; WILLIAMS, Jessica. Focus on form in classroom second language acquisition. Cambridge: Cambridge University Press, 1998. p. 15-41.

MARCUSCHI, Luiz. A análise da conversação. São Paulo: Ática. 1996.

NUNAN, David. Task-based syllabus design: selecting, grading and sequencing tasks. In CROOKES, Graham.; GASS, Susan. M. (Eds.). Tasks in a pedagogical context. Cleveland, UK: Multilingual Matters, 1993. p. 55-66.

. Designing tasks for the communicative classroom. Cambridge: Cambridge University Press, 1989. 
PHABHU, NOAN. Second language pedagogy. Oxford: Oxford University Press, 1987.

SAVIGNON, Sandra. Communicative competence: theory and classroom practice. Reading. McGraw-Hill, 2001.

SKEHAN , Peter. Task-based learning and pedagogy. ELT Journal, v. 53, n. 1, p. $232-248,1999$.

STERN, Henry. H. Linguistic theory and language teaching: emergence of a relationship. Fundamental concepts of language teaching. Oxford: Oxford University Press, p.152-187, 1987.

TEIXEIRA DA SILVA, VERA. L. Fluência oral: imaginário, construto e realidade num curso de letras/LE. 2002. Tese (Doutorado em Linguística Aplicada) - Instituto de Estudos da Linguagem, Universidade Estadual de Campinas, Campinas, 2000.

VAN DEN BRANDEN, Kris. Task-based language education: from theory to practice. Cambridge: Cambridge University Press, 2007.

VIEIRA-ABRAHÃO, Maria H. Um estudo da interação aluno-aluno em atividades em pares ou em grupos na aula de língua estrangeira. 1992. Dissertação (Mestrado em Linguística Aplicada) - Instituto de Estudos da Linguagem, Universidade Estadual de Campinas, Campinas, 1992.

Conflitos e incertezas do professor de língua estrangeira na renovação de sua prática da sala de aula. 1996. Tese (Doutorado em Linguística Aplicada) - Instituto de Estudos da Linguagem, Universidade Estadual de Campinas, Campinas, 1996.

VYGOTSKY, Lev. S. A formação social da mente: o desenvolvimento dos processos psicológicos superiores. São Paulo: Martins Fontes. 2000.

WIDDOWSON, Henry. G. $O$ ensino de línguas para a comunicação. Tradução: José Carlos Paes de Almeida Filho. Campinas: Pontes. 1991. 
Rita C. Barbirato; Elaine R. Mateus

- Knowledge of language and ability for use. Applied Linguistics, v. 10, n. 2, p. 128 - 137, 1989.

- Skills, abilities and contexts of reality. Annual Review of Applied Linguistics, v. 18, p. 323- 333, 1998.

WILLIS, David; WILLIS, Jane. Doing task-based teaching. New York: Oxford University Press:, 2007.

\section{Apêndice A: Teste cloze inicial}

Fill in the gaps with a word that gives meaning to the text:

\section{The norman conquest of England}

A very important event in British history took place in 1066: the Battle of Hastings. Edward the Confessor, the King of England, Norman and half Anglo-Saxon. He left no son of his half promissed his throne Duke William of Normandy, who was cousin on his mother's side.

Edward sent Harold Godwinsson, who the son of one of the powerful Anglo-Saxon noblemen, the Earl Wessex, to swear allegiance to William. However, in 1066, when King Edward took the crown of England the support of the Anglo-Saxon aristocracy.

When William of Normandy heard this was very angry and he decided invade England with an army of 7.000

On 14 October 1066 the Normans the Anglo-Saxons at Hastings. It was a long, difficult battle. After eight hours of battle, Harold Godwisson killed when an arrow struck him the eye. After this the Saxons were defeated, and after his victory William was called "the Conqueror". He became king of England on Christmas Day 66. 


\section{Apêndice B: Teste cloze final}

I. Read the passage below and fill in the gaps with a word that gives meaning to the text:

Henry VIII's attempt to father a son
Henry __ above all to have a healthy son, so that the Tudor

Henry VIII's attempt to father a son
Henry __ above all to have a healthy son, so that the Tudor family could continue power and civil war would be avoided. His father Henry VII, arranged for him his ___ Prince Arthur, and Henry had a Catherine of Aragon, widow of son wanted. Henry VIII then fell , Mary, but not the Boleyn, so in 1527 he sent his Archbishop of Canterbury, Cardinal Wolsey, to ask the Pope to let him Catherine. But the Pope

Henry's request because remarriage was by the Bible. Henry got angry. He removed Wosley from office and appointed Thomas

Cranmer as Archbishop. Cranmer declared Henry never really married to Catherine, so Henry divorced Catherine and married Anne Boleyn in June 1533. She to a girl three months later. Her name was Elizabeth. As is well Known, Henry kept marrying four more after Anne Boleyn. Thomas Cranmer faithfully and loyally King Henry VIII get rid his wives on five occasions, including having two of them executed.

Submetido em: 19/02/13

Aceito em: 04/04/14

Title: The development of pre-service teachers' communicative competence in a task-based course 